\title{
Vitamin D levels and risk of delirium
}

\section{A mendelian randomization study in the UK Biobank}

Kirsty Bowman, PhD, * Lindsay Jones, MBBS, * Luke C. Pilling, PhD, João Delgado, PhD, George A. Kuchel, MD, Luigi Ferrucci, MD, PhD, Richard H. Fortinsky, PhD, and David Melzer, MBBCh, PhD

Neurology ${ }^{\circledR}$ 2019;92:e1387-e1394. doi:10.1212/WNL.0000000000007136

\section{Abstract}

\section{Objective}

To estimate effects of vitamin $\mathrm{D}$ levels on incident delirium hospital admissions using inherited genetic variants in mendelian randomization models, which minimize confounding and exclude reverse causation.

\section{Methods}

Longitudinal analysis using the UK Biobank, community-based, volunteer cohort (2006-2010) with incident hospital-diagnosed delirium (ICD-10 F05) ascertained during $\leq 9.9$ years of follow-up of hospitalization records (to early 2016). We included volunteers of European descent aged 60-plus years by end of follow-up. We used single-nucleotide polymorphisms previously shown to increase circulating vitamin D levels, and APOE variants. Cox competing models accounting for mortality were used.

\section{Results}

Of 313,121 participants included, 544 were hospitalized with delirium during follow-up. Vitamin D variants were protective for incident delirium: hazard ratio $=0.74$ per $10 \mathrm{nmol} / \mathrm{L}$ (95\% confidence interval $0.62-0.87, p=0.0004)$ increase in genetically instrumented vitamin $\mathrm{D}$, with no evidence for pleiotropy (mendelian randomization-Egger $p>0.05$ ). Participants with $\geq 1$ APOE $\varepsilon 4$ allele were more likely to develop delirium (e.g., $\varepsilon 4 \varepsilon 4$ hazard ratio $=3.73,95 \%$ confidence interval 2.68-5.21, $p=8.0 \times 10^{-15}$ compared to $\left.\varepsilon 3 \varepsilon 3\right)$, but there was no interaction with vitamin $\mathrm{D}$ variants.

\section{Conclusions and relevance}

In a large community-based cohort, there is genetic evidence supporting a causal role for vitamin $\mathrm{D}$ levels in incident delirium. Trials of correction of low vitamin $\mathrm{D}$ levels in the prevention of delirium are needed.

\section{Correspondence}

Prof. Melzer

D.Melzer@exeter.ac.uk

\section{RELATED ARTICLE}

\section{Editorial}

Vitamin D: A novel protective factor for delirium?

Page 553

\section{MORE ONLINE}

\section{CME Course}

NPub.org/cmelist

*These authors contributed equally to this work.

From the Epidemiology and Public Health Group (K.B., L.J., L.C.P., J.D., D.M.), University of Exeter Medical School, Royal Devon \& Exeter Hospital, Exeter, UK; UConn Center on Aging (G.A.K., R.H.F., D.M.), University of Connecticut, Farmington, CT; and National Institute on Aging (L.F.), Baltimore, MD.

Go to Neurology.org/N for full disclosures. Funding information and disclosures deemed relevant by the authors, if any, are provided at the end of the article. 


\section{Glossary}

$\mathbf{C I}=$ confidence interval; $\mathbf{G R S}=$ genetic risk score; HR = hazard ratio; $\mathbf{I C D}-\mathbf{1 0}=$ International Classification of Diseases, Tenth Revision; IVW = inverse-variance weighted; $\mathrm{MR}=$ mendelian randomization; $\mathbf{p Q T L}=$ protein quantitative trait loci; $\mathbf{s H R}=$ subhazard ratio; SNP = single-nucleotide polymorphism.

Delirium is an acute decline in cognitive function, with a rapid onset of symptoms. ${ }^{1}$ It is relatively common in later life and is associated with substantially increased morbidity and mortality. ${ }^{1,2}$ Interest has grown in the potential role of vitamin $\mathrm{D}$ in protecting against cognitive decline. A recent metaanalysis reported that low vitamin D levels are associated with poorer cognition and accelerated cognitive decline, ${ }^{3}$ perhaps through vitamin D's anti-inflammatory properties. ${ }^{4,5}$ In observational studies, low levels of vitamin $\mathrm{D}$ have been associated with an increased likelihood of delirium in patients with hip fracture ${ }^{6}$ and for hospital-acquired, new-onset delirium. ${ }^{7}$ Genetically increased levels of vitamin D have been linked to reduced risk of Alzheimer disease in one study. ${ }^{8}$ However, evidence for the potential role of genetically increased vitamin $\mathrm{D}$ levels in reducing risk of incident delirium in large population-based studies is lacking.

Studies of outcomes in later life are susceptible to confounding and reverse causation, when associations with a risk factor are due to the effects of underlying pathology rather than being causal. Inherited genetic variants can provide stronger evidence for potential causal effect on an outcome- a technique known as mendelian randomization (MR). ${ }^{9}$

To apply genetic analyses, variants altering risk factor status are needed, which have their mode of action through the risk factor only. ${ }^{9}$ Here, we applied MR approaches to test vitamin $\mathrm{D}$ associations with incident delirium in an exceptionally large sample of older UK Biobank participants of European descent, in order to clarify the likely causal significance. We also accounted for $A P O E$ status.

\section{Methods}

Between 2006 and 2010, UK Biobank recruited 503,325 community-based volunteers (aged 40-70 years) from across the United Kingdom. ${ }^{10}$ Genetic data were available on 488,377 UK Biobank participants, of whom 451,427 participants were identified as of European ancestry using selfreport and genetics data. ${ }^{11}$ Given that $7.5 \%$ of the participants were from non-European ancestries and from diverse lineages, we focused on participants from European ancestry.

\section{Standard protocol approvals, registrations, and patient consents}

Participants provided informed consent for data linkage to hospital inpatient admissions, cancer registrations, and death registrations. Ethical approval for the UK Biobank study was obtained from the North West Multi-Centre Research Ethics
Committee. The current analysis was part of UK Biobankapproved project 14631 on aging well.

Delirium diagnosis was ascertained using ICD-10 code F05 in hospital discharge data. Participants who had a delirium episode before baseline interview were excluded from analyses $(n=51)$. Participants were eligible for inclusion if they reached the age of 60 within the follow-up period (up to February 16, 2016) (excluded $n=138,251$ ). Participants with incident delirium had to be aged 60 years or older at diagnosis because incident cases before age 60 years are rare (excluded $n=3$ ). One participant was excluded because they were missing an assessment date. This left 313,121 participants for the analysis.

Genotyping quality control and imputation were performed centrally by UK Biobank. Genetic variants rs 429358 and rs7412 were used to define APOE haplotypes. Genetic variants for circulating $25(\mathrm{OH}) \mathrm{D}$ concentration (vitamin $\mathrm{D}$ ) were extracted from 2 studies: 4 from Vimaleswaran et al. ${ }^{12}$ and 6 from a more recent report by Jiang et al., ${ }^{13}$ which included a larger sample size but log-transformed the vitamin D levels (the 4 loci from Vimaleswaran are included in the 6 from Jiang) (only one variant from each locus was included, and only if the final meta-analysis $p$ value was $<5 \times 10^{-8}$; all included variants had sufficient imputation quality $[>0.4]$ and no deviation from Hardy-Weinberg equilibrium $[p>1 \times$ $\left.10^{-6}\right]$ in the UK Biobank participants). We checked for consistency across both results and used the weights from Vimaleswaren to obtain the hazard ratio (HR) per nanomoles/ liter of vitamin D. To confirm that the genetic risk score (GRS) was predictive for vitamin $\mathrm{D}$, we used data from the InCHIANTI Study, a cohort study of aging in the Tuscany region of Italy in which both vitamin $\mathrm{D}$ and genetic variants were available.

The primary MR analysis methods were performed using $\mathrm{R}$ (v3.4.1) package "MendelianRandomization" (v0.2.2). Genetic variants were individually assessed for their association with incident delirium, and the natural log-transformed subhazard ratios (sHRs) were aligned with the vitamin D-raising allele and effect from the previously published studies and submitted to the "mr_input()" function. We used the penalized robust inverse-variance weighted (IVW) regression result as the primary analysis, and checked the penalized weighted median and penalized robust MR-Egger analyses for consistency in the effect estimate, and finally whether the MREgger intercept significantly differed from zero to test for potential pleiotropy (i.e., whether the effect of the singlenucleotide polymorphisms [SNPs] on delirium is via a pathway other than the risk factor under assessment ${ }^{14}$ ). The exponential of the IVW regression coefficient was derived 
(due to the earlier logging of the estimates for the MR analysis) to give the risk change (HR) per unit of vitamin $\mathrm{D}(\mathrm{nmol} / \mathrm{L})$. The UK National Institute for Clinical Excellence concluded that "there is consensus that levels below $25 \mathrm{nmol} / \mathrm{L}(10 \mathrm{ng} / \mathrm{ml})$ qualify as 'deficient,' but beyond this there is currently no standard definition of 'optimal' $25(\mathrm{OH}) \mathrm{D}$ levels. Some sources suggest that levels above $50 \mathrm{nmol} / \mathrm{L}(30 \mathrm{ng} / \mathrm{ml})$ are 'sufficient,' while $70-80 \mathrm{nmol} / \mathrm{L}(28-32 \mathrm{ng} / \mathrm{ml})$ is 'optimal." ${ }^{\prime 15}$ We therefore chose to present the effect of genetically instrumented vitamin D levels per $10 \mathrm{nmol} / \mathrm{L}$ increase, as this is a clinically relevant level. To derive the risk of incident delirium per 10 $\mathrm{nmol} / \mathrm{L}$ of vitamin $\mathrm{D}$, we raised the HR to the power 10 .

In secondary analyses of vitamin D, we created a GRS by summing the number of vitamin $\mathrm{D}$-increasing alleles carried by each UK Biobank participant, weighted by the effect on circulating vitamin D levels using PLINK v1. $9^{16}$; we used the 6 loci from Jiang et al. ${ }^{13}$ We confirmed that our vitamin D GRS was associated with vitamin D levels in blood assays from 1,161 participants from the InCHIANTI aging study, using a linear regression model adjusted for age, sex, and study site, with natural log-transformed vitamin D levels as the outcome (coefficient $=1.29,95 \%$ confidence interval $[\mathrm{CI}] 0.80-1.78$, $\left.p=3 \times 10^{-7}\right)$.

Estimates of associations between the vitamin $\mathrm{D}$ variants and incident delirium were from Fine and Gray competing risks regression ${ }^{17}$ adjusted for age, sex, genotyping array, and principal components $1-5$ of the genotyping data to account for population structure. Estimates of associations between $A P O E$ haplotype and incident delirium were adjusted for age, sex, genotyping array, and principal components $1-5$. In sensitivity analyses, we investigated the effects of adjusting for self-reported time spent in the sun in the summer, excluding one of each pair of participants related to the third degree or closer (identified by KING kinship analysis ${ }^{18}$ ), adjusting for calcium GRS ( $\mathrm{n}=5$ of 7 variants published in reference 19 as rs1550532 were not available in the UK Biobank version 2 genetic data release, and we excluded rs 1570669 because it is located at the same locus as rs6013897 in the vitamin D score on chromosome 20), excluding participants with diagnosed dementia from analyses (ICD-10 codes F00, F01, F02, F03, and G30), investigating the effect of a rare variant in CYP2R1 (rs117913124) ${ }^{20}$ with incident delirium, and rerunning the analysis using a noncompeting risk Cox model. To investigate whether the vitamin D-increasing variants may be acting via other pathways, we first took advantage of recent large pQTL (protein quantitative trait loci) studies to determine whether these loci are associated with proteins other than vitamin $\mathrm{D}^{21,22}$ and, second, the catalog of published genome-wide association studies. ${ }^{23}$ Stata v14.1 (StataCorp, College Station, TX) was used for competing risks regression.

\section{Data availability}

Data are available from the UK Biobank after submitting an application (ukbiobank.ac.uk/register-apply/). The syntax for conducting the analysis is available on request.

\section{Results}

Of 313,121 participants included in analyses, 544 had at least one incident episode of delirium recorded in hospital discharge data. The mean time to delirium diagnosis was 4.6 years (SD 1.6 years). Mean age at baseline for all the participants was 61.7 years (SD 4.7 years) and $53.8 \%$ of the sample were women (table 1). The mean age at delirium diagnosis was 71.6 years (SD 4.12 years), the minimum and maximum age was 60.0 and 77.8 years, respectively. The overall follow-

Table 1 Characteristics of the sample

\begin{tabular}{|c|c|c|c|}
\hline & All & Participants with incident delirium & Nondelirium controls \\
\hline No. (\%) & 313,121 & 544 & 312,577 \\
\hline Age, $y$, mean (SD) at baseline & $61.7(4.7)$ & $64.9(4.0)$ & $61.7(4.7)$ \\
\hline Female, $\mathbf{n}(\%)$ & $168,505(53.8)$ & $208(38.2)$ & $168,297(53.8)$ \\
\hline Prevalent dementia, n (\%) & $150(0.1)$ & $6(1.1)$ & $144(0.1)$ \\
\hline Mean no. of $25(\mathrm{OH}) \mathrm{D}$-increasing alleles ${ }^{\mathrm{a}}$ & $0.269(0.068)$ & $0.269(0.068)$ & $0.260(0.072)$ \\
\hline \multicolumn{4}{|l|}{ APOE haplotype, n (\%) } \\
\hline$\varepsilon 2 \varepsilon 2$ & $1,965(0.6)$ & $3(0.6)$ & $1,962(0.6)$ \\
\hline$\varepsilon 2 \varepsilon 3$ & $38,753(12.4)$ & $54(9.9)$ & $38,699(12.4)$ \\
\hline$\varepsilon 2 \varepsilon 4$ & $7,800(2.5)$ & $13(2.4)$ & $7,787(2.5)$ \\
\hline$\varepsilon 3 \varepsilon 3$ & $183,295(58.5)$ & $266(48.9)$ & $183,029(58.6)$ \\
\hline$\varepsilon 3 \varepsilon 4$ & $73,882(23.6)$ & $168(30.9)$ & $73,714(23.6)$ \\
\hline$\varepsilon 4 \varepsilon 4$ & $7,412(2.4)$ & $40(7.4)$ & $7,372(2.4)$ \\
\hline
\end{tabular}

a These are from the genetic risk score weighted for the effect of each variant on $25(\mathrm{OH}) \mathrm{D}$ levels. 
Figure Vitamin D-increasing genetic variants are associated with reduced risk of incident delirium

A

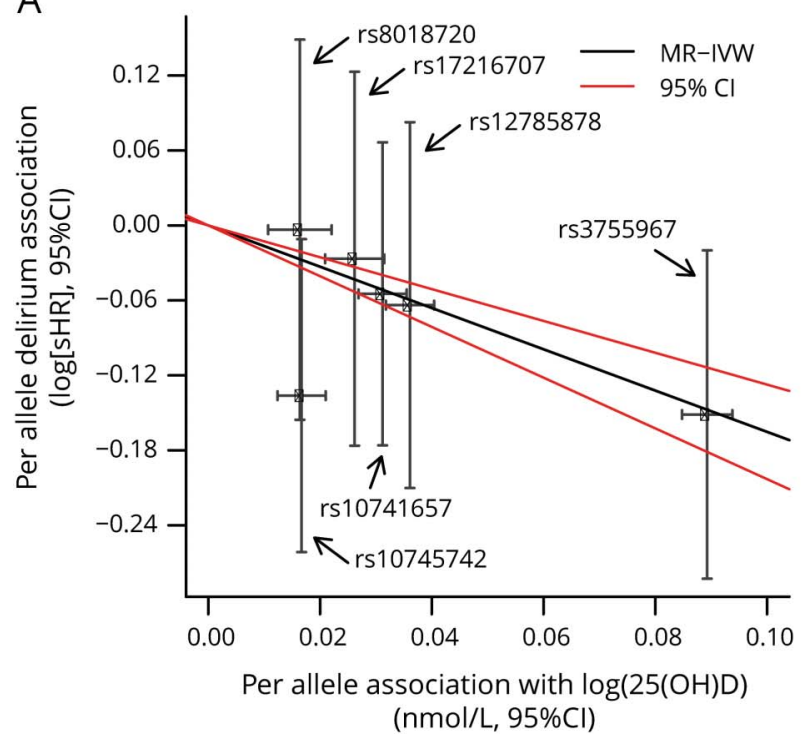

B

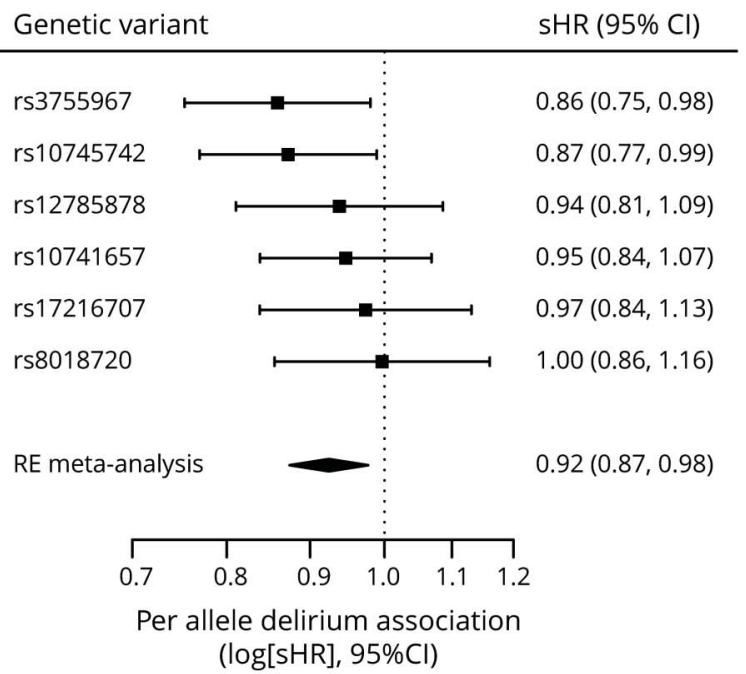

Jiang et al. ${ }^{13}$ (2018) found 6 genetic variants to affect circulating 25(OH)D (vitamin D) levels. (A) The effect of previously published per-allele effect of each variant on vitamin D levels is plotted on the $\mathrm{x}$-axis, and the association of the same variant with incident delirium (logged hazard ratio) is plotted on the $y$-axis, with the mendelian randomization inverse-weighted (MR-IVW) regression line and 95\% confidence intervals (Cls) also show. (B) The per-allele association with incident delirium is shown for each vitamin D-raising genetic variant, with a random-effects (RE) meta-analysis of the 6 variants also shown. sHR = subhazard ratio.

up was up to 9.9 years. There were 11,669 deaths during the follow-up period (198 deaths after delirium). Within 1 year after the delirium diagnosis, 151 (27.8\%) had died, and within 5 years, $196(36.3 \%)$ had died.

Vitamin D-increasing alleles were associated with decreased risk of delirium (figure, $\mathrm{A}$ and $\mathrm{B}$ and table 2): the IVW regression coefficient was -1.65 (95\% CI -2.03 to $-1.27, p=3.5$ $\times 10^{-17}$ ) (table 3$)$. We observed consistent effect directions in the other MR methods (penalized weighted median coefficient $=-1.71,95 \% \mathrm{CI}-3.04$ to -0.38 ) (penalized robust MR-Egger coefficient $=-1.90,95 \% \mathrm{CI}-2.61$ to -1.19$)$, and no significant pleiotropy, as tested by the MR-Egger method $(p>0.05)$.

Because the units from Jiang et al. are natural log-transformed vitamin $\mathrm{D}$ levels and therefore are not easily interpretable, we also applied MR methods to the 4 largest-effect variants published by Vimaleswaran et al. ${ }^{12}$ who provide the per-allele effect on each nanomole/liter of vitamin D levels. This relationship was consistent when we used 4 vitamin $\mathrm{D}$-increasing alleles from Vimaleswaran et al. ${ }^{12}$ (table 3). The sHR for incident delirium per unit increase in genetically instrumented $25(\mathrm{OH}) \mathrm{D}$ levels $(\mathrm{nmol} / \mathrm{L})$ was 0.970 (the exponential of the penalized

Table 2 Six vitamin D-raising genetic variant associations with incident delirium

\begin{tabular}{|c|c|c|c|c|c|c|c|c|c|c|}
\hline \multirow[b]{2}{*}{ Gene } & \multirow[b]{2}{*}{ SNP } & \multirow[b]{2}{*}{ CHR } & \multirow[b]{2}{*}{ POS } & \multirow[b]{2}{*}{ EA } & \multirow[b]{2}{*}{ OA } & \multirow[b]{2}{*}{ EAF } & \multicolumn{2}{|c|}{ Vitamin D association $^{a}$} & \multicolumn{2}{|c|}{ Delirium association $^{b}$} \\
\hline & & & & & & & $\beta(95 \% \mathrm{Cl})$ & $p$ Value & sHR $(95 \% \mathrm{Cl})$ & $p$ Value \\
\hline$G C$ & rs3755967 & 4 & 72828262 & C & $\mathrm{T}$ & 0.71 & $0.089(0.085-0.094)$ & $4.7 \times 10^{-300}$ & $0.860(0.754-0.980)$ & 0.024 \\
\hline CYP2R1 & rs10741657 & 11 & 14871454 & A & G & 0.40 & $0.031(0.027-0.036)$ & $2.1 \times 10^{-46}$ & $0.947(0.839-1.069)$ & 0.380 \\
\hline NADSYN1/DHCR7 & rs12785878 & 11 & 70845097 & $\mathrm{~T}$ & G & 0.21 & $0.036(0.032-0.040)$ & $3.8 \times 10^{-62}$ & $0.938(0.810-1.086)$ & 0.390 \\
\hline AMDHD1 & rs10745742 & 12 & 94882660 & $\mathrm{~T}$ & C & 0.62 & $0.017(0.012-0.021)$ & $1.9 \times 10^{-14}$ & $0.873(0.770-0.989)$ & 0.033 \\
\hline SEC23A & rs8018720 & 14 & 38625936 & G & $C$ & 0.18 & $0.016(0.011-0.022)$ & $4.7 \times 10^{-9}$ & $0.997(0.856-1.160)$ & 0.960 \\
\hline CYP24A1 & rs17216707 & 20 & 52165769 & $\mathrm{~T}$ & $C$ & 0.81 & $0.026(0.021-0.031)$ & $8.1 \times 10^{-23}$ & $0.974(0.838-1.131)$ & 0.730 \\
\hline
\end{tabular}

Abbreviations: $\beta=$ per-allele effect on log-transformed nmol/L of 25(OH)D; $\mathrm{CHR}=$ chromosome; $\mathrm{Cl}=$ confidence interval; $\mathrm{EA}=$ effect allele $($ vitamin $\mathrm{D}$-increasing); $\mathrm{EAF}=$ effect allele frequency in UK Biobank sample included in analyses; OA = other allele; POS = position on genome build 37 ; sHR = per additional effect allele subhazard ratio on risk of incident delirium; SNP = single-nucleotide polymorphism.

a Summary statistics from jiang et al. ${ }^{13}$ (2018).

b Summary statistics from the current study. 
Table 3 MR results for the vitamin D-raising genetic variants against incident delirium

\begin{tabular}{|c|c|c|c|}
\hline MR method ${ }^{a}$ & $\beta(95 \% \mathrm{Cl})$ & $p$ Value & $\mathrm{SHR}^{\mathrm{b}}(95 \% \mathrm{CI})$ \\
\hline \multicolumn{4}{|c|}{ Four vitamin D variants from Vimaleswaran $2013(\mathrm{nmol} / \mathrm{L})^{c}$} \\
\hline IVW & $\begin{array}{l}-0.0307(-0.0477 \text { to } \\
-0.0137)\end{array}$ & $4.0 \times 10^{-4}$ & $\begin{array}{l}0.970 \\
(0.953-0.986)\end{array}$ \\
\hline Weighted median & $\begin{array}{l}-0.0326(-0.0636 \text { to } \\
-0.0017)\end{array}$ & $3.9 \times 10^{-2}$ & $\begin{array}{l}0.968 \\
(0.938-0.998)\end{array}$ \\
\hline MR-Egger & $\begin{array}{l}-0.0302(-0.0507 \text { to } \\
-0.0097)\end{array}$ & $3.9 \times 10^{-3}$ & $\begin{array}{l}0.970 \\
(0.951-0.990)\end{array}$ \\
\hline MR-Egger (intercept) & $-0.0013(-0.0756$ to 0.073$)$ & $9.7 \times 10^{-1}$ & $\begin{array}{l}0.999 \\
(0.927-1.076)\end{array}$ \\
\hline \multicolumn{4}{|c|}{ Six vitamin D variants from Jiang et al. ${ }^{13}(2018)$ (natural log-transformed nmol/L) ${ }^{d}$} \\
\hline IVW & $\begin{array}{l}-1.6521(-2.0303 \text { to } \\
-1.2739)\end{array}$ & $3.5 \times 10^{-17}$ & \\
\hline Weighted median & $\begin{array}{l}-1.7067(-3.0376 \text { to } \\
-0.3759)\end{array}$ & $1.2 \times 10^{-2}$ & \\
\hline MR-Egger & $\begin{array}{l}-1.9003(-2.6117 \text { to } \\
-1.1888)\end{array}$ & $2.1 \times 10^{-7}$ & \\
\hline MR-Egger (intercept) & $0.0147(-0.0372$ to 0.0666$)$ & $5.8 \times 10^{-1}$ & \\
\hline
\end{tabular}

Abbreviations: $\mathrm{Cl}$ = confidence interval; IVW = inverse-variance weighted; MR = mendelian randomization; sHR = subhazard ratio.

${ }^{a}$ MR methods $=$ penalized robust.

${ }^{\mathrm{b}}$ sHR: risk of incident delirium per nmol/L increase in genetically instrumented vitamin D (25[OH]D) levels.

${ }^{c} \beta=\log (\mathrm{HR})$ against $25(\mathrm{OH}) \mathrm{D}$ levels $(\mathrm{nmol} / \mathrm{L})$.

${ }^{d} \beta=\log (\mathrm{HR})$ against 25(OH)D levels (natural log-transformed nmol/L); sHR only included for the Vimaleswaran effect because those based on the Jiang results could be misleading (because of the vitamin D levels being natural log-transformed).

robust IVW regression coefficient -0.0307 ; table 3) (95\% CI $0.953-0.986)$ : incident delirium risk is therefore reduced by $3 \%$ per $\mathrm{nmol} / \mathrm{L}$ increase in genetically instrumented vitamin $\mathrm{D}$. The risk reduction per $10 \mathrm{nmol} / \mathrm{L}$ increase was $0.736(95 \% \mathrm{CI}$ $0.620-0.873$ ), calculated by raising 0.970 to the power 10 . We observed consistent effect directions in the other MR methods (penalized weighted median $\mathrm{sHR}=0.968,95 \%$ CI 0.938-0.998) (penalized robust MR-Egger sHR $=0.970,95 \% \mathrm{CI}$ 0.951-0.990), and no significant pleiotropy, as tested by the MREgger method $(p>0.05)$ (table 3). Using a GRS for vitamin D, we found a consistent association $(\mathrm{sHR}=0.88$ per SD of vitamin D GRS, 95\% CI 0.81-0.96, $p=0.0044)$.

Participants with one or more APOE $\varepsilon 4$ allele were at a substantial increased risk of incident delirium (table 4). Those homozygote for $A P O E \& 4$ (i.e., $2 \varepsilon 4$ copies present) had markedly increased risks ( $\mathrm{sHR}=3.73,95 \%$ CI $2.68-5.21, p=$ $\left.8.0 \times 10^{-15}\right)$; $\varepsilon 4$ heterozygotes (i.e., $\varepsilon 3 \varepsilon 4$ ) were at intermediate risk $\left(\mathrm{sHR}=1.58,95 \% \mathrm{CI} 1.30-1.91, p=3.8 \times 10^{-6}\right)$. The APOE associations were independent of the vitamin $\mathrm{D}$ genetic risks and

Table 4 APOE haplotype associations with delirium

\begin{tabular}{|c|c|c|c|c|}
\hline \multirow[b]{2}{*}{ APOE haplotype ${ }^{a}$} & \multirow[b]{2}{*}{$\operatorname{sHR}(95 \% \mathrm{CI})$} & \multirow[b]{2}{*}{$p$ Value } & \multicolumn{2}{|c|}{ Adjusted for vitamin D GRS ${ }^{b}$} \\
\hline & & & sHR $(95 \% \mathrm{Cl})$ & $p$ Value \\
\hline$\varepsilon 2 \varepsilon 2$ & $1.07(0.34-3.35)$ & $9.0 \times 10^{-1}$ & $1.08(0.35-3.36)$ & $9.0 \times 10^{-1}$ \\
\hline$\varepsilon 2 \varepsilon 3$ & $0.96(0.72-1.29)$ & $7.9 \times 10^{-1}$ & $0.96(0.72-1.29)$ & $7.9 \times 10^{-1}$ \\
\hline$\varepsilon 2 \varepsilon 4$ & $1.16(0.67-2.03)$ & $6.0 \times 10^{-1}$ & $1.17(0.67-2.04)$ & $5.9 \times 10^{-1}$ \\
\hline$\varepsilon 3 \varepsilon 3$ & 1 & & 1 & \\
\hline$\varepsilon 3 \varepsilon 4$ & $1.58(1.3-1.91)$ & $3.8 \times 10^{-6}$ & $1.58(1.3-1.92)$ & $3.5 \times 10^{-6}$ \\
\hline$\varepsilon 4 \varepsilon 4$ & $3.73(2.68-5.21)$ & $8.0 \times 10^{-15}$ & $3.74(2.69-5.22)$ & $7.0 \times 10^{-15}$ \\
\hline
\end{tabular}

Abbreviations: $\mathrm{Cl}$ = confidence interval; GRS = genetic risk score; $\mathrm{sHR}=$ subhazard ratio.

${ }^{a} \varepsilon 1 \varepsilon 2$ and $\varepsilon 1 \varepsilon 4$ not reported because of low numbers and no participants with incident delirium.

${ }^{\mathrm{b}}$ Vitamin D genetic risk score (6 variants) sHR 0.88 (95\% Cl 0.81-0.96), $p$ value 3.80e-03. 
were not substantively changed (table 4). There was no interaction with vitamin $\mathrm{D}$ variants.

\section{Sensitivity analyses}

To test the robustness of the vitamin $\mathrm{D}$ association with delirium, we adjusted for self-reported time spent outdoors in the summer; excluded one of each pair of participants related to the third degree or closer; and adjusted for a GRS of 5 known calcium level-altering variants that have not been reported to be associated with vitamin D levels. Results were not substantively changed (table 5) and the calcium-altering variants were not associated with delirium. Excluding 150 cases of dementia diagnosed before the assessment visit had no effect on the association between the vitamin D GRS, $A P O E$ genotype, and incident delirium (table 5). We tested the association between a low-frequency variant in CYP2R1 (rs117913124, vitamin D-decreasing minor allele frequency $2.77 \%$ in the studied sample) identified in a separate study ${ }^{19}$ and incident delirium, and found there was no significant association ( $\mathrm{sHR} 1.05,95 \%$ CI $0.74-1.49, p=0.78$ ). However, because we had only $80 \%$ power to detect an effect of 1.6 (at $\alpha=0.05$, with 544 patients with delirium and 312,577 controls, using the genetic association study power calculator ${ }^{24}$ ), this variant may have a smaller effect on delirium that we were not powered to detect. In noncompeting risk models, the point estimates for the 6 vitamin $\mathrm{D}$ genetic variants with incident delirium were slightly different, although the overall conclusion remained the same (rs3755967 HR 0.86, 95\% CI 0.76-0.98; rs 10745742 HR 0.87 , 95\% CI $0.77-0.99$; rs12785878 HR 0.94, 95\% CI 0.81-1.08; rs10741657 HR 1.06, 95\% CI 0.93-1.19; rs 17216707 HR 1.03, 95\% CI
0.88-1.19; rs8018720 HR 1.00, 95\% CI 0.86-1.17). The MR analyses using results from noncompeting risk models were also consistent when using the 4 variants from Vimaleswaran: the $\mathrm{HR}$ for incident delirium per $10 \mathrm{nmol} / \mathrm{L}$ increase in genetically instrumented 25(OH)D levels was 0.737 (95\% CI $0.620-0.872)$. Finally, we found that vitamin D-increasing loci (or proxies) are not associated with other protein levels in 2 recent large pQTL studies, ${ }^{21,22}$ although one of the 6 SNPs (rs17216707) is also associated with estimated glomerular filtration rate. ${ }^{25}$ Excluding this SNP from the MR analysis makes no meaningful difference (new penalized robust MRIVW regression estimate using only 5 variants $=-1.6399,95 \%$ $\mathrm{CI}-1.887$ to $-1.392, p=1.4 \times 10^{-38}$ ).

\section{Discussion}

In this large-scale prospective study, participants with genetically determined higher vitamin D levels had substantially lower risks of incident hospitalized episodes of delirium. Because MR analysis greatly reduces confounding and excludes reverse causation, ${ }^{9,13}$ our results suggest that interventional trials to increase vitamin $\mathrm{D}$ levels may be justified to reduce risk of delirium. In addition, participants carrying an APOE \&4 allele were at increased risk of incident delirium, likely contributing to the increased risk of dementia observed after an episode of delirium. However, the effect of vitamin D-related variants was not altered by $A P O E$ status.

The association between vitamin $\mathrm{D}$ and delirium is plausible as vitamin $\mathrm{D}$ receptors are distributed within the hippocampus, hypothalamus, cortex, and subcortex, and evidence suggests

Table 5 Hazard ratios for incident delirium using a vitamin D genetic risk score and APOE following a number of sensitivity analyses

\begin{tabular}{|c|c|c|c|}
\hline Exposure & Analysis & sHR $(95 \% \mathrm{CI})$ & $p$ Value \\
\hline \multicolumn{4}{|c|}{ Vitamin D genetic risk score (6 variants) } \\
\hline & Adjustment for time spent outdoors in the summer $(n=295,049)$ & $0.89(0.82-0.97)$ & $1.1 \times 10^{-2}$ \\
\hline & Unrelated participants $(n=262,560)$ & $0.90(0.82-0.98)$ & $2.1 \times 10^{-2}$ \\
\hline & Adjustment for calcium genetic risk score (5 variants) & $0.88(0.81-0.96)$ & $4.4 \times 10^{-3}$ \\
\hline & Excluding prevalent dementia $(n=150)$ at baseline & $0.88(0.80-0.96)$ & $3.8 \times 10^{-3}$ \\
\hline \multicolumn{4}{|c|}{$\begin{array}{l}\text { APOE haplotype }{ }^{a} \text { excluding prevalent } \\
\text { dementia }(n=150) \text { at baseline }\end{array}$} \\
\hline & $\varepsilon 2 \varepsilon 2$ & $1.09(0.35-3.40)$ & $8.8 \times 10^{-1}$ \\
\hline & $\varepsilon 2 \varepsilon 3$ & $0.96(0.71-1.28)$ & $7.7 \times 10^{-1}$ \\
\hline & $\varepsilon 2 \varepsilon 4$ & $1.18(0.68-2.06)$ & $5.6 \times 10^{-1}$ \\
\hline & $\varepsilon 3 \varepsilon 3$ & 1 & \\
\hline & $\varepsilon 3 \varepsilon 4$ & $1.59(1.31-1.93)$ & $2.7 \times 10^{-6}$ \\
\hline & $\varepsilon 4 \varepsilon 4$ & $3.80(2.73-3.80)$ & $3.6 \times 10^{-15}$ \\
\hline
\end{tabular}

Abbreviations: $\mathrm{Cl}$ = confidence interval; SHR = subhazard ratio.

${ }^{a} \varepsilon 1 \varepsilon 2$ and $\varepsilon 1 \varepsilon 4$ not reported because of low numbers and no participants with incident delirium. 
a variety of neurophysiologic and neuroprotective mechanisms. $^{26}$ In addition, behavioral and attention disorders, and accelerated aging have been documented in vitamin $\mathrm{D}$ receptor knockout transgenic mice models. ${ }^{27-29}$ Furthermore, evidence indicates that vitamin D may modulate serotonin synthesis. ${ }^{30}$ Serotonin is involved in regulating a range of behaviors and brain function and has been indicted to have a role in delirium. $^{31}$ Therefore, the effect of vitamin $\mathrm{D}$ on delirium may be in part attributable to its effect on serotonin synthesis. ${ }^{30,31}$ Low levels of vitamin $\mathrm{D}$ have been observationally associated with an increased likelihood of delirium in patients with hip fracture and for hospital-acquired, new-onset delirium. ${ }^{6,7}$

A number of studies have used MR approaches to estimate the effects of low vitamin D levels on cognitive outcomes. Of note, a recent analysis showed no association between vitamin $\mathrm{D}$ and global or memory cognition using an MR approach, although the vitamin D score (synthesis) was composed of 2 SNPs. ${ }^{29}$ Genetically increased levels of vitamin D (4 SNPs score), however, were associated with a reduced risk of Alzheimer disease at nominal statistical significance. ${ }^{8}$ Here, we use MR approaches to estimate the effects of vitamin D levels on risk of delirium, thereby minimizing confounding and excluding reverse causation. Although we cannot rule out pleiotropy (the vitamin $\mathrm{D}$-increasing loci affect delirium risk via other mechanistic routes), we found no evidence in 2 large recent $\mathrm{pQTL}$ studies ${ }^{21,22}$ that these loci affect other protein levels, and excluding the one variant associated with estimated glomerular filtration rate in another genome-wide association study $^{25}$ did not significantly change the result.

A recent meta-analysis reported that there was no association between $A P O E$ and delirium, although the number of delirium cases included was smaller than in the present study. ${ }^{28}$ Here, we showed carriers of an APOE $\varepsilon 4$ allele were at an increased risk of delirium independent of a dementia diagnosis in our analyses, suggesting that APOE may constitute a shared mechanism between the 2 conditions. $A P O E$ \&4 status may therefore be a useful addition to estimating risk of developing delirium, especially in designing intervention trials.

There are a number of limitations with our study. First, serum vitamin D levels were not available for the UK Biobank participants and therefore the genetic variants could not be assessed concurrently with vitamin $\mathrm{D}$ levels and delirium. However, we confirmed that the genetic variants we studied were strongly associated with blood levels of vitamin $\mathrm{D}$ in the InCHIANTI Study (see methods). Second, MR analysis has important assumptions and limitations, in particular that the genetic instruments are only associated with the outcome via the exposure under examination, and the association between the exposure and outcome is linear; however, MR-Egger analysis provided no evidence of pleiotropy, and variants were not associated with covariates in our analyses. Finally, UK Biobank participants tended to be healthier than the UK general population at baseline, and therefore our number of delirium cases is lower than expected and estimates may be less applicable to frail older groups. ${ }^{32}$

In the data available, the vast majority of the participants had one delirium episode; 32 participants had $\geq 2$ delirium episodes. Our analysis is based on the first delirium episode. Future studies could examine risk factors for recurrent events. The methods in this analysis were used to estimate the linear effect of vitamin D levels around the population average; future studies could examine the nonlinear effects of vitamin D and delirium.

In this study, genetic evidence suggests that higher vitamin $\mathrm{D}$ levels may be a substantial causal protective factor for incident delirium. Clinical studies are needed to confirm this. Delirium and dementia share a common risk factor in APOE genotype, which may contribute to the high rates of incident dementia observed after an episode of delirium.

\section{Author contributions}

K. Bowman and L.C. Pilling conducted the statistical analysis. K. Bowman: design or conceptualization of the study, analysis or interpretation of the data, drafting or revising the manuscript for intellectual content. L. Jones: design or conceptualization of the study, analysis or interpretation of the data, drafting or revising the manuscript for intellectual content. L.C. Pilling: design or conceptualization of the study, analysis or interpretation of the data, drafting or revising the manuscript for intellectual content. J. Delgado: drafting or revising the manuscript for intellectual content. G.A. Kuchel: drafting or revising the manuscript for intellectual content. L. Ferrucci: drafting or revising the manuscript for intellectual content. R.H. Fortinsky: drafting or revising the manuscript for intellectual content. D. Melzer: design or conceptualization of the study, analysis or interpretation of the data, drafting or revising the manuscript for intellectual content.

\section{Acknowledgment}

This research has been conducted using the UK Biobank Resource, under application 14631. The authors thank the UK Biobank participants and coordinators for this unique dataset and Dr. Andrew R. Wood for his work identifying the UK Biobank participants of European descent.

\section{Study funding}

Supported by UK Medical Research Council award MR/ M023095/1 to D.M., and L.F. is supported by the Intramural Research Program of the NIH National Institute on Aging.

\section{Disclosure}

The authors report no disclosures relevant to the manuscript. Go to Neurology.org/N for full disclosures.

\section{Publication history}

Received by Neurology May 15, 2018. Accepted in final form November 14, 2018. 


\section{References}

1. Inouye SK. Delirium in older persons. N Engl J Med 2006;354:1157-1165.

2. McCusker J, Cole M, Abrahamowicz M, Primeau F, Belzile E. Delirium predicts 12month mortality. Arch Intern Med 2002;162:457.

3. Goodwill AM, Szoeke C. A systematic review and meta-analysis of the effect of low vitamin D on cognition. J Am Geriatr Soc 2017;65:2161-2168.

4. Mangin M, Sinha R, Fincher K. Inflammation and vitamin D: the infection connection. Inflamm Res 2014;63:803-819.

5. Yin K, Agrawal DK. Vitamin D and inflammatory diseases. J Inflamm Res 2014;7:69-87.

6. Torbergsen AC, Watne LO, Frihagen F, Wyller TB, Brugaard A, Mowe M. Vitamin deficiency as a risk factor for delirium. Eur Geriatr Med 2015;6:314-318.

7. Quraishi SA, Litonjua AA, Elias KM, et al. Association between pre-hospital vitamin D status and hospital-acquired new-onset delirium. Br J Nutr 2015;113:1753-1760.

8. Christopher SC, Traylor M, Malik R, Dichgans M, Burgess S, Markus HS. Modifiable pathways in Alzheimer's disease: mendelian randomisation analysis. BMJ 2017;359:j5375.

9. Paternoster L, Tilling K, Davey Smith G. Genetic epidemiology and mendelian randomization for informing disease therapeutics: conceptual and methodological challenges. PLoS Genet 2017;13:1-9.

10. Sudlow C, Gallacher J, Allen N, et al. UK Biobank: an open access resource for identifying the causes of a wide range of complex diseases of middle and old age. PLoS Med 2015;12:e1001779.

11. Pilling LC, Kuo CL, Sicinski K, et al. Human longevity: 25 genetic loci associated in 389,166 UK Biobank participants. Aging 2017;9:2504-2520.

12. Vimaleswaran KS, Berry DJ, Lu C, et al. Causal relationship between obesity and vitamin D status: bi-directional mendelian randomization analysis of multiple cohorts. PLoS Med 2013;10:e1001383.

13. Jiang X, O'Reilly PF, Aschard H, et al. Genome-wide association study in 79,366 European-ancestry individuals informs the genetic architecture of 25-hydroxyvitamin D levels. Nat Commun 2018;9:260.

14. Bowden J, Smith GD, Burgess S. Mendelian randomization with invalid instruments: effect estimation and bias detection through Egger regression. Int J Epidemiol 2015; 44:512-525.

15. Cancer Research UK. Expert Paper 3: vitamin D. Support Doc NICE PH32 [Internet]. 2010;25. Available at: nice.org.uk/guidance/ph32/documents/expert-paper-3-vitamin-d2. Accessed August 2018.

16. Purcell S, Neale B, Todd-Brown K, et al. PLINK: a tool set for whole-genome association and population-based linkage analyses. Am J Hum Genet 2007;81:559-575.

17. Fine JP, Gray RJ. A proportional hazards model for the subdistribution of a competing risk. J Am Stat Assoc 1999;94:496-509.
18. Manichaikul A, Mychaleckyj JC, Rich SS, Daly K, Sale M, Chen WM. Robust relationship inference in genome-wide association studies. Bioinformatics 2010;26: 2867-2873.

19. O'Seaghdha $\mathrm{CM}, \mathrm{Wu} \mathrm{H}$, Yang $\mathrm{Q}$, et al. Meta-analysis of genome-wide association studies identifies six new loci for serum calcium concentrations. PLoS Genet 2013;9: e1003796.

20. Manousaki D, Dudding T, Haworth S, et al. Low-frequency synonymous coding variation in CYP2R1 has large effects on vitamin D levels and risk of multiple sclerosis. Am J Hum Genet 2017;101:227-238.

21. Sun BB, Maranville JC, Peters JE, et al. Genomic atlas of the human plasma proteome. Nature 2018;558:73-79.

22. Yao C, Chen G, Song C, et al. Genome-wide mapping of plasma protein QTLs identifies putatively causal genes and pathways for cardiovascular disease. Nat Commun 2018;9:3268.

23. MacArthur J, Bowler E, Cerezo M, et al. The new NHGRI-EBI catalog of published genome-wide association studies (GWAS catalog). Nucleic Acids Res 2017;45: D896-D901.

24. Johnson JL. GAS Power Calculator. 2017. Available at: csg.sph.umich.edu/abecasis/ gas_power_calculator. Accessed August 2018.

25. Pattaro C, Teumer A, Gorski M, et al. Genetic associations at 53 loci highlight cell types and biological pathways relevant for kidney function. Nat Commun 2016;7: $1-19$.

26. Aspell N, Lawlor B, O'Sullivan M. Is there a role for vitamin D in supporting cognitive function as we age? Proc Nutr Soc 2018;77:124-134.

27. Keisala T, Minasyan A, Lou YR, et al. Premature aging in vitamin D receptor mutant mice. J Steroid Biochem Mol Biol 2009;115:91-97.

28. Tuohimaa D, Meagher D, Williams J, Mulligan O, McCarthy G. A systematic review and meta-analysis of the association between the apolipoprotein $\mathrm{E}$ genotype and delirium. Psychiatr Genet 2016;26:53-59.

29. Maddock J, Zhou A, Cavadino A, et al. Vitamin D and cognitive function: a mendelian randomisation study. Sci Rep 2017;7:13230.

30. Patrick RP, Ames BN. Vitamin D and the omega-3 fatty acids control serotonin synthesis and action, part 2: relevance for $\mathrm{ADHD}$, bipolar disorder, schizophrenia, and impulsive behavior. FASEB J 2015;29:2207-2222.

31. van Mast RC, Fekkes D. Serotonin and amino acids: partners in delirium pathophysiology? Semin Clin Neuropsychiatry 2000;5:125-131.

32. Fry A, Littlejohns TJ, Sudlow C, Doherty N, Allen N. OP41 The representativeness of the UK Biobank cohort on a range of sociodemographic, physical, lifestyle and healthrelated characteristics. BMJ 2016;70(suppl 1):2016. 


\section{Neurology}

\section{Vitamin D levels and risk of delirium: A mendelian randomization study in the UK Biobank}

Kirsty Bowman, Lindsay Jones, Luke C. Pilling, et al. Neurology 2019;92;e1387-e1394 Published Online before print February 15, 2019

DOI 10.1212/WNL.0000000000007136

This information is current as of February 15, 2019

\section{Updated Information \&} Services

Supplementary Material

\section{References}

Citations

Subspecialty Collections

Permissions \& Licensing

Reprints including high resolution figures, can be found at: http://n.neurology.org/content/92/12/e1387.full

Supplementary material can be found at: http://n.neurology.org/content/suppl/2019/12/30/WNL.0000000000007 136.DC1

This article cites 30 articles, 1 of which you can access for free at: http://n.neurology.org/content/92/12/e1387.full\#ref-list-1

This article has been cited by 1 HighWire-hosted articles: http://n.neurology.org/content/92/12/e1387.full\#\#otherarticles

This article, along with others on similar topics, appears in the following collection(s):

All epidemiology

http://n.neurology.org/cgi/collection/all_epidemiology

All Genetics

http://n.neurology.org/cgi/collection/all_genetics

Delirium

http://n.neurology.org/cgi/collection/delirium

Information about reproducing this article in parts (figures,tables) or in its entirety can be found online at:

http://www.neurology.org/about/about_the_journal\#permissions

Information about ordering reprints can be found online:

http://n.neurology.org/subscribers/advertise

Neurology ${ }^{\circledR}$ is the official journal of the American Academy of Neurology. Published continuously since 1951, it is now a weekly with 48 issues per year. Copyright Copyright ( 2019 The Author(s). Published by Wolters Kluwer Health, Inc. on behalf of the American Academy of Neurology.. All rights reserved. Print ISSN: 0028-3878. Online ISSN: 1526-632X.

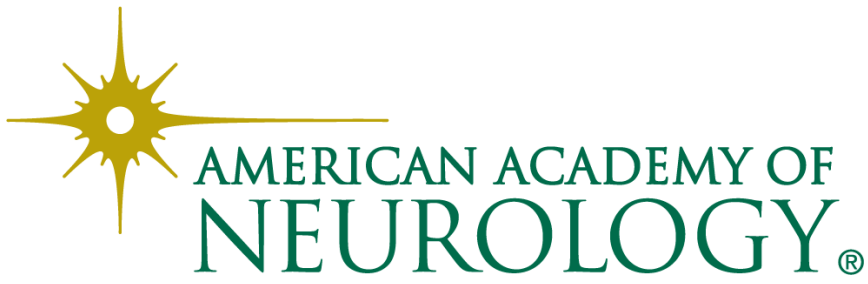

